\title{
Cogitare
Enfermagem
}

\section{EDUCAÇÃO PERMANENTE E SUA INTERFACE COM MELHORES PRÁTICAS EM ENFERMAGEM NA ATENÇÃO PRIMÁRIA À SAÚDE}

\author{
Carine Vendruscolo ${ }^{1}$ (i) \\ Kátia Jamile da Silva ${ }^{1}$ (i) \\ Juliana Andréa Duarte Araújo' ${ }^{1}$ (c) \\ Mônica Ludwig Weber ${ }^{1}$ (])
}

\section{RESUMO}

Objetivo: analisar a implicação do processo de educação permanente para o desenvolvimento das melhores práticas em enfermagem na Atenção Primária à Saúde.

Metodologia: estudo quanti-qualitativo, realizado em duas macrorregiões de saúde do estado de Santa Catarina - Brasil. A amostra quantitativa foi de 216 enfermeiros, de 97 municípios. Os dados foram obtidos mediante aplicação de questionário e analisados via estatística descritiva. As informações qualitativas foram produzidas via grupos focais, em três municípios, e analisadas com auxílio do Atlas.ti 8.0®.

Resultados: 174 enfermeiros (80,6\%) possuem especialização. 200 (92\%) participam de processos de educação permanente, incluindo troca de experiências e atualização, com destaque para o Telessaúde. Os discursos originaram cinco codegroups: compartilhar saberes e experiências; conhecimento e experiência qualificam a prática; educação: libertação e mudança; integração ensino-serviço; tempo para aprender.

Conclusão: os processos de educação permanente tangenciam concepções da educação libertadora e apontam para a experiência e uso de evidências.

DESCRITORES: Atenção Primária à Saúde; Cuidados de Enfermagem; Educação Continuada; Enfermagem Baseada em Evidências; Educação.

\section{EDUCACIÓN PERMANENTE Y SU INTERFAZ CON LAS MEJORES PRÁCTICAS DE ENFERMERÍA EN LA ATENCIÓN PRIMARIA A LA SALUD}

\section{RESUMEN:}

Objetivo: analizar la implicancia del proceso de educación permanente para el desarrollo de las mejores prácticas de Enfermería en la Atención Primaria de la Salud. Metodología: estudio cuanti-cualitativo, realizado en dos macroregiones de salud del estado de Santa Catarina - Brasil. La muestra cuantitativa estuvo compuesta por 216 enfermeros, de 97 municipios. Los datos se obtuvieron mediante la aplicación de un cuestionario y se los analizó a través de estadística descriptiva. Los datos cualitativos se produjeron a través de grupos focales, en tres municipios, y se los analizó con la ayuda del programa Atlas.ti 8.0®. Resultados: 174 enfermeros (80,6\%) poseen alguna especialización. 200 (92\%) participan de procesos de educación permanente, incluyendo intercambio de experiencias y actualización, destacándose el programa Telessaúde (Telesalud). Los discursos originaron cinco code groups: compartir saberes y experiencias; el conocimiento y la experiencia califican la práctica; educación: liberación y cambio; integración enseñanza-servicio; y tiempo para aprender. Conclusión: los procesos de educación permanente entran en contacto tangencial con conceptos de la educación liberadora y apuntan a la experiencia y al uso de evidencias.

DESCRIPTORES: Atención Primaria de la Salud; Atención de Enfermería; Educación Continua; Enfermería Basada en Evidencias; Educación. 
Fundamentada nos pressupostos pedagógicos formulados pela Organização Panamericana de Saúde e pela Organização Mundial da Saúde (OPAS/OMS), na década de 1980, a Educação Permanente em Saúde (EPS) se orienta pela aprendizagem significativa. Isso implica dar vazão às questões que são expressivas aos atores protagonistas das práticas de produção à saúde, com vistas a mudanças significativas no processo de trabalho das equipes de saúde e base nas suas necessidades e conhecimentos prévios ${ }^{(1)}$.

Com tais contornos, em nível internacional, as bases da EPS também convergem com a Educação Interprofissional (EIP), seguindo pressupostos da pedagogia crítica e métodos de aprendizagem interativos. Baseia-se na perspectiva sociológica para promover a articulação entre as diferentes profissões da área da saúde ${ }^{(2)}$. Autor ${ }^{(3)}$ apresenta a interprofissionalidade como conceito emergente da EIP e das práticas interprofissionais, o que demanda reavaliar as relações entre as profissões, investir na compreensão mútua e explorar meios para combinar o conhecimento, para melhorar a prestação de serviços, a segurança do usuário e a qualidade do cuidado(4).

No Brasil, os movimentos para fortalecimento do Sistema Único de Saúde (SUS) são marcados por políticas indutoras da reorientação da formação, aproximando ensino e serviço, especialmente, relacionadas ao processo de trabalho na Atenção Primária à Saúde (APS) (1). Particular destaque deve ser investido à Política Nacional de Educação Permanente em Saúde (PNEPS), cuja base pedagógica sustenta práticas que valorizam a emancipação e o protagonismo dos sujeitos nos processos de trabalho em equipe, com vistas às práticas que favoreçam a interprofissionalidade ${ }^{(2-4)}$.

A enfermagem tem contribuído expressivamente na qualidade e efetividade dos sistemas de saúde e para a construção da identidade do SUS, pois além de representar a maior força de trabalho, está presente na maioria das ações que envolvem o cuidado à população, como a consulta de enfermagem, a educação em saúde, a imunização, entre outras ${ }^{(5)}$. O trabalho da enfermagem caracteriza-se como coletivo e demanda a colaboração com outras profissões e trabalhadores do campo da saúde. O saber consolidado da enfermagem é a base do seu cotidiano laboral e orienta a tomada de decisão no processo de trabalho, mediante desafios oriundos das dimensões do cuidado, da gestão e da investigação(6).

Na atualidade, há uma ampla discussão sobre o eufemismo dos conceitos de melhores práticas e da Enfermagem de Prática Avançada $(E P A)^{(7)}$, este último relacionado ao aumento da acessibilidade e da cobertura na APS, mantendo a qualidade do cuidado. No Canadá, tais discussões iniciaram no final dos anos 1960 e na Europa e Ásia, durante a década de $1980^{(8)}$. No bojo de tais polêmicas, o conceito de melhores práticas em enfermagem emerge no Brasil como possibilidade de qualificar o cuidado e como um caminho para o desenvolvimento e o exercício da criatividade, aliada à experiência cotidiana e às habilidades ou competências implícitas ${ }^{(9)}$.

As melhores práticas se caracterizam por uma tríade, configurando-se como uma técnica ou metodologia que, por meio da experiência ou da investigação, apresenta confiabilidade comprovada para um bom resultado, levando em conta as necessidades do usuário/paciente ${ }^{(5)}$. Assim, para realizar a melhor prática, é necessário reconhecer a opção mais adequada às situações e contextos específicos, a partir da utilização racionada de recursos, para atingir resultados desejados. O profissional se guia pela melhor evidência atualizada para o manejo clínico, considerando um contexto específico, a exemplo dos protocolos de cuidado na APS(5,9).

Assim, investigar e reconhecer o potencial das melhores práticas para ampliar o debate sobre a EPA implica reconhecer o que tem sido realizado pelo enfermeiro nessa direção e como as iniciativas relacionadas ao processo de formação podem contribuir para 
sua conduta. Com base nessa constatação, o objetivo deste estudo é analisar a implicação do processo de educação permanente para o desenvolvimento das melhores práticas em enfermagem na APS.

\section{MÉTODO}

Estudo quanti-qualitativo, cuja etapa quantitativa foi desenvolvida em Unidades de APS com Estratégia Saúde da Família (ESF), nos 131 municípios que compõem duas das nove Macrorregiôes de Saúde do estado de Santa Catarina-SC, Brasil. A coleta de dados foi realizada entre abril de 2018 e agosto de 2019.

A população foram os enfermeiros que atuam nas Unidades de Saúde dos municípios integrantes às Macrorregiões. Foi critério de inclusão atuar como enfermeiro na ESF do município há pelo menos um ano. Foram excluídos os enfermeiros que, no período da coleta, estavam em licença ou afastados do serviço por qualquer motivo. O cálculo amostral da etapa quantitativa respeitou o nível de significância $5 \%$, intervalo de confiança $95 \%$ e proporção de 50\%, estimando 205 participantes.

Os dados qualitativos foram obtidos mediante grupos focais com enfermeiros que atuavam na APS de três municípios representativos das Macrorregiões, estabelecidos por sorteio, com as seguintes características: um com até 50.000 habitantes, um com 35.001140.000 habitantes, e um com mais de 140.000 habitantes, adequados conforme viabilidade de acesso. Foram realizados três grupos em cada município.

Para a coleta dos dados quantitativos, foi utilizado questionário tipo survey, estruturado, no Google Forms, com variáveis que contemplavam o perfil sociodemográfico, processo de trabalho e as práticas desenvolvidas pelos enfermeiros. Este foi encaminhado via e-mail para todos os enfermeiros das equipes das Macrorregiões, em parceria com a Associação Brasileira de Enfermagem - Seção Santa Catarina (ABEn/SC) e com as Gerências Regionais de Saúde. No conteúdo do e-mail, foi anexado o Termo de Consentimento Livre e Esclarecido. $\mathrm{O}$ acesso e resposta ao survey formalizava sua anuência à participação na pesquisa.

Foram convidados a fazer parte da etapa quantitativa do estudo 231 enfermeiros; 15 foram excluídos por não atenderem aos critérios, totalizando 216 enfermeiros respondentes. Dentre os 131 municípios contatados, em 34 não foram obtidas respostas, totalizando $74,04 \%$ dos municípios contemplados nas Macrorregiões.

A etapa qualitativa contou com a participação de 29 enfermeiros, sendo 19 do município de maior porte, cinco do de médio porte e cinco do de pequeno porte. A produção dos dados foi encerrada de acordo com a saturação teórica. Os grupos focais tiveram duração média de duas horas, conduzidos por um pesquisador, um relator e apoiadores; e as falas dos participantes foram gravadas e transcritas na íntegra.

Para o procedimento analítico quantitativo, foi utilizado o software SPSS 21.0. As informações qualitativas foram tratadas mediante análise temática(10), seguindo: préanálise, exploração do material e tratamento dos dados. Foram inseridas no Atlas.ti Qualitative Data Analysis \& Research Software, versão 8.0. A partir dos documents foi possível selecionar trechos significativos, com base nos objetivos do estudo, associandoos a codes identificadores, que originaram cinco codegroups: (1) compartilhar saberes e experiências; (2) conhecimento e experiência qualificam a prática; (3) educação: libertação e mudança; (4) integração ensino-serviço e (5) tempo para aprender.

O projeto foi aprovado pelo Comitê de Ética em Pesquisa em Seres Humanos da instituição proponente do estudo, sob parecer $n^{\circ} 2.380 .748$. Para garantir o anonimato 
dos participantes, as falas serão designadas pela letra E de entrevista (ou de enfermeiro), seguida por número de ordem e a letra $M$ de município, seguida de número de ordem, sendo M1 referente ao município de menor porte e assim sucessivamente.

\section{RESULTADOS}

A Tabela 1 reflete a participação dos enfermeiros da APS das Macrorregiões Oeste e Meio Oeste de Santa Catarina em ações de EPS. Eles referem participar de ações de educação permanente em saúde em grande medida $(n=200 / 92,6 \%)$, sendo o Telessaúde (ferramenta utilizada como possibilidade de educação à distância) a fonte mais acessada $(n=120 / 55 \%)$.

Tabela 1 - Participação dos enfermeiros da APS das Macrorregiões Oeste e Meio Oeste de Santa Catarina em ações de EPS, utilização do Telessaúde e atividades de preceptoria, $(n=216)$. Xanxerê, SC, Brasil, 2019

\begin{tabular}{lcc} 
Variáveis & $\mathbf{n}$ & $\%$ \\
\hline Participação em ações de EPS* & & \\
\hline Sim & 16 & 7,4 \\
\hline Não & 200 & 92,6 \\
\hline Utiliza o Telessaúde & & \\
\hline Sim & 120 & 55,6 \\
\hline Não & 96 & 44,4 \\
\hline Participação em atividades de preceptoria & & \\
\hline Não & 92 & 42,6 \\
\hline Sim, com supervisão direta e indireta do professor & 70 & 32,4 \\
\hline Sim, apenas como visita técnica & 17 & 7,9 \\
\hline Sim, com supervisão direta do professor & 6 & 2,8 \\
\hline Sim, somente com supervisão indireta do professor & 31 & 14,4 \\
*incluindo troca de experiências em reunião de equipe, estudo em grupo e cursos de atualização. \\
Fonte: autor (2019).
\end{tabular}

As falas dos enfermeiros ilustram essa preferência:

[...] aquele curso do Telessaúde é maravilhoso, eu estou no último módulo, agora já estou finalizando, ele fala como deveria ser a APS perfeita dos sonhos [...] a importância de uma formação pautada nas diretrizes do SUS, a importância da integração ensino-serviço para o profissional e como isso faz diferença. (E9M2).

Os participantes chamam a atenção para a sobrecarga do trabalho cotidiano na APS, destacando a falta de tempo para o estudo, a reflexão e a pesquisa: 
[...] mesmo na corrida sempre, na sobrecarga de tarefas, esses momentos [de estudo coletivo] nos fazem refletir sobre o que fazemos e onde queremos chegar. (E2M1)

Você até sabe o ponto que está tendo dificuldade, tanto com o paciente ou no [desempenho] profissional, mas você não para e pensa: vamos buscar uma qualificação, uma melhoria. (E1M1)

[...] quando você está no momento do trabalho, você está sobrecarregado, você fica no automático e não reflete muita coisa. [...] no dia a dia, acho que dificilmente passa um dia que você faça algum procedimento ou rotina que você não pense: ah, mas eu posso fazer assim que é melhor! (E2M1)

Reconhecem o conhecimento como importante elemento para a qualificação das práticas e nessa direção, destacam as melhores práticas como as que favorecem o cuidado ao paciente, a partir dessa qualificação:

[...] quanto maior é o teu conhecimento, melhor é a tua prática [...] essas melhores práticas são o que você pode fazer de melhor para aquele paciente, que está precisando daquele cuidado. (E1M1)

O estudo também evidenciou a impressão dos enfermeiros sobre o fato de que o distanciamento da universidade favorece a perda gradativa de certas habilidades:

Essa troca é importante para a gente se atualizar, porque fora das universidades as coisas vão dificultando, precisa ter uma reciclagem. (E4M1)

Com tais inferências, reconhecem a importância da presença da universidade nos serviços e da possibilidade de acompanharem os professores e estudantes em estágio, destacando a necessidade de maior integração ensino-serviço:

A universidade é importante nesse processo [...] esse movimento que nos tira da unidade, do atendimento e da rotina diária, para refletir e tentar melhorar. (E7M3)

[...] cada um [equipe] foca na sua área especifica! Precisa compartilhar mais [...] precisa de um alinhamento entre o serviço e a universidade. (E8M2). Eu destacaria a importância de melhorar a comunicação do ensino-serviço. (E10M2)

[...] a gente sabe e ouve muito falar do mestrado que é difícil, mas a gente não imagina a proporção, só depois que está lá [...] o aprendizado é imenso, tu mudas a concepção sobre muitas coisas $[\ldots](E 11 \mathrm{M} 2)$

Isso é reforçado pelos comentários acerca da participação dos enfermeiros em atividades de preceptoria - acompanhamento de estudantes nos estágios profissionalizantes - na qualidade de profissional de serviço, aspecto que nos dados quanti também foi destaque, com um número considerável de enfermeiros que referiu receber estudantes, com supervisão direta e indireta do professor ( $n=70 / 32,4 \%$ ).

[...] quando você recebe esse estudante no ambiente na Unidade, você nunca entra num diálogo e sai sem aprender alguma coisa, então, nós também, enquanto enfermeiros, aprendemos nessa integração ensino-serviço, porque a gente também repensa as nossas práticas [...] você estuda, ensina, orienta e aprende também, essa integração que existe é fundamental, não me vejo sem essa parte na APS. (E12M2)

A Tabela 2 apresenta as características sociodemográficas, de escolaridade e de trabalho dos enfermeiros que atuam na APS, no local de estudo. 
Tabela 2 - Características sociodemográficas e de trabalho dos enfermeiros da APS das Macrorregiões Oeste e Meio Oeste de Santa Catarina $(n=216)$. Xanxerê, SC, Brasil, 2019

Características

n $\%$

\begin{tabular}{lcc}
\hline Sexo & & \\
\hline Feminino & 203 & 94 \\
\hline Masculino & 13 & 6 \\
\hline Idade - média (desvio padrão) & 36,26 & $(7,06)$ \\
\hline Escolaridade & & \\
\hline Graduação & 29 & 13,4 \\
\hline Especialização & 174 & 80,6 \\
\hline Residência & 1 & 0,5 \\
\hline Mestrado & 12 & 5,6 \\
\hline Tempo de atuação na APS (anos) -mediana (intervalo interquartil) & $8,50(4-13)$
\end{tabular}

Fonte: autor (2019).

Aidade dos participantes variou de 26 a 36 anos, maioria mulheres, com pós-graduação latu sensu ( $n=174 / 80,60 \%)$. Na etapa qualitativa, eram todas mulheres. Chamou atenção o fato de que um percentual considerável dos enfermeiros da Macrorregião possui pósgraduação strito sensu ( $n=12 / 5,60 \%)$. Nesse cenário, cumpre destacar que a região está distante cerca de 500 quilômetros da capital do estado, durante muito tempo considerada polo de formação na área de enfermagem.

Os enfermeiros compartilham de um ideário sobre a educação permanente, como possibilidade de troca de experiências, de compartilhamento de saberes com outras profissões e a partir de situações da prática:

Eu acho muito bom esses encontros, a gente sempre quer ficar mais, trocar experiências, conhecer a realidade do outro. (E3M1).

[...] ter claro a importância da Educação Permanente, a partir da realidade vivida. (E3M1)

[...] eu acredito na divisão das coisas, acho que é só começar, conversar com os outros profissionais. Por comandar a equipe, acho que a gente pode delegar funções, compartilhar práticas e conhecimentos. (E6M3)

Percebem a educação como prática empoderadora, que favorece a atitude crítica e libertadora e, nesse contexto, reconhecem a enfermagem como uma profissão composta por oprimidos, fazendo alusão à obra do educador brasileiro Paulo Freire:

[...] Freire fala disso, dos oprimidos, nós somos uma classe extremamente poderosa em função de tudo o que a gente faz, do que a gente pode mexer, mas a gente está oprimido [...] toda vez que alguém tenta fazer alguma coisa diferente, é perseguido politicamente [...] Enquanto está ali apagando os incêndios, não paramos para refletir e pensar e eu acho que é o que a questão político-partidária faz com a gente: 'Não deixa elas perceberem o poder que elas tem porque elas vão provocar mudanças [...]'. (E5M3).

A Figura 1 apresenta os codegroups relacionados à implicação do processo de formação/educação permanente para o desenvolvimento das melhores práticas em enfermagem na APS, os quais serão discutidos a seguir. 


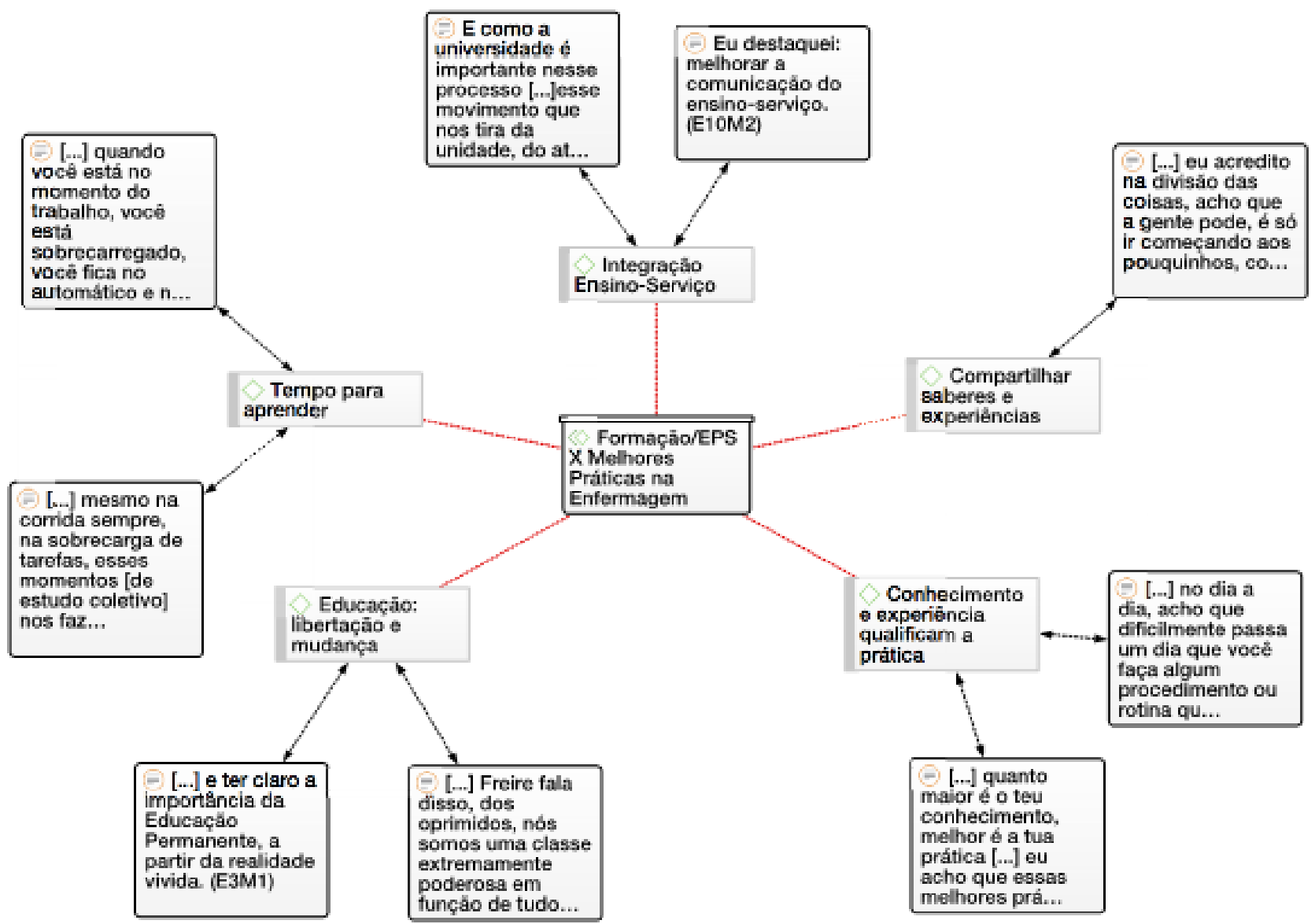

Figura 1 - Codegroups relacionados à implicação do processo de formação/educação permanente para o desenvolvimento das melhores práticas em enfermagem na Atenção Primária à Saúde, Xanxerê, SC, Brasil, 2019

Fonte: autor (2019).

Considerando-se as Macrorregiões investigadas, situadas na parte do estado mais distante da capital, chamou a atenção o quantitativo, ainda tímido, mas crescente de enfermeiros que estão acessando cursos de mestrado. Nessa direção, é importante destacar que, até recentemente, as oportunidades de formação na modalidade stricto sensu voltadas para a enfermagem somente estavam acessíveis na capital do estado. Em 2017, foi criado um curso de Mestrado Profissional (MP) em Enfermagem, em uma instituição pública do Oeste de SC, sendo o primeiro na região(11). Para dar conta das demandas sociais, políticas e econômicas, associadas à qualificação de trabalhadores em serviço, os MP visam a formação voltada à "prática profissional avançada e transformadora de procedimentos e processos aplicados, por meio da incorporação do método científico, habilitando o profissional para atuar em atividades técnico-científicas e de inovação"(12:20).

No Brasil, o Conselho Federal de Enfermagem (COFEN) apostou na qualificação de cerca de 500 profissionais ao longo de quatro anos e passou a apoiar pesquisas por meio dos MP em parceria com a Coordenação de Aperfeiçoamento de Pessoal de Nível Superior (CAPES), sobretudo, direcionadas à temática Sistematização da Assistência de Enfermagem $(\mathrm{SAE})^{(13)}$. No estado em que ocorreu a pesquisa, duas instituições públicas foram contempladas neste edital, uma delas situada na Macrorregião do estudo. Em 2019, a CAPES lançou novo edital e, novamente, a instituição foi contemplada. 
A enfermagem representa mais da metade do número de profissionais na área da saúde no Brasil e o número cresce 12,5\% ao ano. Apesar de nas últimas décadas haver uma tendência ao aumento da participação masculina na profissão, predominam as mulheres, com influência na feminilização da saúde no Brasil ${ }^{(14-15)}$. O enfermeiro opera na APS a partir de um processo de trabalho que aponta para o protagonismo, de bases técnico-científicas, legais e políticas, mediante práticas comprometidas com o bem-estar social. Seu trabalho está organizado em dimensões que permeiam o cuidado, a educação e o gerenciamento(16). Em se tratando da APS, estas implicam a educação e o trabalho interprofissional(17). A pesquisa evidencia alguns aspectos da EIP, presentes no ideário dos enfermeiros, que destacam o trabalho em equipe, a colaboração entre profissionais ${ }^{(17)}$ (representada no code 1) e a integração com a universidade (representada no code 4), deixando claros os pressupostos teóricos, filosóficos e políticos que orientam a EPS(18-19).

Os espaços de ação e de reflexão sobre a prática se configuram em duas unidades de cooperação e transformação - o trabalho e a educação - que, integrados, promovem a transformação da realidade ${ }^{(11,19)}$. Nessa perspectiva, os enfermeiros parecem buscar apoio para aprimoramento das suas práticas com a troca de informações e a partir das situações da prática, mediante o acúmulo de experiências ou acesso de orientações via Telessaúde. Eles parecem comprometidos com a necessidade de agir (fazer) e refletir (pensar sobre a ação) a partir dos problemas cotidianos, com vistas ao aprimoramento da sua práxis, de forma coerente com a perspectiva crítica e libertadora da educação $(\text { code } 3)^{(1,20)}$.

$\mathrm{Na}$ APS, a articulação entre serviços e ações para o cuidado integral pode ser potencializada pela utilização das Tecnologias de Informação e Comunicação (TIC), como é o caso do Telessaúde. No Brasil, gradativamente, a tecnologia, sob diversas modalidades, tem sido incorporada à assistência e à gestão em saúde, inclusive a distância, tendo como uma das principais preocupações a redução de custos $^{(21)}$. Na pesquisa, tal possibilidade de acesso a informação também se destaca, coerente com outro estudo realizado na região(1).

As concepções dos enfermeiros quanto aos aspectos da educação dos profissionais de saúde vão de encontro à visão hegemônica, que concebe a educação como transmissão unidirecional de saberes e atitudes (concepção bancária) em que se espera do educador (e do profissional de saúde) o provimento da informação científica atualizada e do educando (e do usuário) um papel passivo e obediente de apreensão das informações e orientações para execução das prescrições ${ }^{(20)}$. Com tal delineamento, o papel dos educandos/usuários seria entender e executar as informações e prescrições determinadas pelo educador/ profissional(22). Os resultados do estudo, por outro lado, chamam a atenção em relação à percepção de que o enfermeiro, por vezes, assume uma condição de opressão, fortalecida por interesses políticos que operam para que ele não se empodere, mantendo-o ocupado (sobrecarregado) e sem tempo para estudar ${ }^{(20)}$.

Foi um achado importante para o desenvolvimento das práticas de enfermagem a compreensão dos grupos sobre a importância de receber estudantes no cenário em que opera a APS. Ao considerar a importância da integração ensino-serviço, recentemente, a Associação Brasileira de Enfermagem (ABEn), juntamente com o Conselho Nacional de Saúde (CNS), elaboraram recomendações às novas Diretrizes Curriculares Nacionais para os cursos de Enfermagem, com o objetivo de qualificar e ampliar a formação dos enfermeiros, considerando o atual cenário da educação em enfermagem no Brasil. Embora as recomendações não especifiquem a função e nem revejam a capacitação em preceptoria, principalmente no que se refere às práticas pedagógicas necessárias ao melhor desempenho do enfermeiro nas práticas pedagógicas, trata-se de um reconhecimento importante para fortalecer a integração ensino-serviço ${ }^{(23)}$.

Todos esses elementos demonstram a implicação da EPS para a qualificação das práticas de enfermagem, sob a ótica dos participantes deste estudo. Eles convergem com estudos que demonstram que as melhores práticas na enfermagem podem ser aprimoradas, mediante a permanente busca pelo conhecimento, todavia, as enfermeiras reconhecem uma sobrecarga diária que influencia na falta de tempo para o estudo (aspecto presente no code 5$)^{(24)}$. Elas, no entanto, reconhecem que uma melhor prática só é possível mediante o 
constante aprimoramento (code 2), que, aliado à experiência que emerge com os anos na função(7), contribui para o cuidado qualificado.

Cumpre destacar que o fazer cuidativo e gerencial da enfermagem necessita de amparo teórico e evidências científicas. Sobre isso, o estudo destacou a preocupação das enfermeiras, que parecem conseguir relacionar o cuidado à sua dimensão subjetiva, imbricada nas relações produzidas no ato de cuidar e/ou gerenciar ${ }^{(25)}$.

O estudo apresentou limitações, como a dificuldade de reunir profissionais de todas as Macrorregiões do estado, bem como analisar os diferentes contextos sociais em que atuam, o que faz refletir sobre a importância da realização de pesquisas que explorem outras dimensões dessa temática.

\section{CONCLUSÃO}

Os processos de educação permanente para o desenvolvimento das melhores práticas em enfermagem na APS na Macrorregião estudada revelam um contingente de profissionais motivados para o aprimoramento profissional. Seu ideário sobre as práticas educativas tangencia concepções da educação libertadora (Freireana) e aponta para a experiência, a colaboração e o uso de evidências no desenvolvimento das melhores práticas.

A busca pela pós-graduação e pela aprendizagem a distância como possibilidade de atualização demonstra não só o interesse pelo aprimoramento profissional, mas que a informaçã̃o e o conhecimento estão acessíveis em regiões mais remotas do Brasil. Dessa forma, reconhecem que dispositivos como o Telessaúde oferecem condições ao desenvolvimento profissional, contemplando temas que implicam melhores práticas.

Os enfermeiros distinguem o papel e a importância da Universidade, mediante a integração ensino serviço e, apesar da sobrecarga de trabalho, demonstram interesse em qualificar sua formação, acessando programas de Mestrado, por exemplo. Isso evidencia que os investimentos nos processos educativos devem ser constituintes do processo de trabalho na APS, pois há um inegável potencial desses movimentos para a construção de novos caminhos trilhados na enfermagem e com impacto no SUS.

\section{REFERÊNCIAS}

1. Weber ML, Vendruscolo C, Adamy EK, Trindade L de L, Heidemann ITSB, Rosset D. Best Nursing Practices: potentials and challenges in an assistential context. RECOM [Internet]. 2019 [acesso em 12 nov 2019]; 9(e:3504). Disponível em: http://dx.doi.org/10.19175/recom.v9i0.3504.

2. Barr H, Ford J, Grey R; Helme M, Low H, Machin A, Reeves, S. Interprofessional education guidelines. London: CAIPE; 2017.

3. D'Amour D, Goulet L, Labadie JF, Martín-Rodriguez LS, Pineault R. A model and typology of collaboration between professionals in healthcare organizations. BMC Health Serv Res. [Internet]. 2008 [acesso em 12 nov 2019]; 8(188). Disponível em: http://doi.org/10.1186/1472-6963-8-188.

4. World Health Organization (WHO). Framework for action on interprofessional education \& collaborative practice. [Internet]. Geneva: WHO; 2010 [acesso em 22 set 2019]. Disponível em: https://www.who.int/ hrh/resources/framework action/en/. 
5. Ferreira SRS, Pércio LAD, Dias VRFG. Atuação do enfermeiro na atenção primária à saúde. Rio de Janeiro: Atheneu, 2017.

6. Pires DEP de. Transformações necessárias para o avanço da enfermagem como ciência do cuidar. Rev bras enferm. [Internet]. 2013 [acesso em 07 de abr 2020]; 66(esp). Disponível em: http://www.scielo.br/ pdf/reben/v66nspe/v66nspea05.pdf.

7. Toso BRG de O, Padilha MI, Breda KL. O eufemismo das boas práticas ou a prática avançada de enfermagem. Esc Anna Nery. [Internet]. 2019 [acesso em 07 abr 2020]; 23(3). Disponível em: http://dx.doi. org/10.1590/2177-9465-ean-2018-0385.

8. Cassiani SH de B, Rosales LK. Initiatives towards advanced practice nursing Implementation in the region of the Americas. Esc Anna Nery. [Internet]. 2016 [acesso em 07 abr 2020]; 20(4). Disponível em: http://doi.org/10.5935/1414-8145.20160081.

9. World Health Organization (WHO). Um guia para identificar e documentar melhores práticas em programas de planejamento familiar. [Internet]. Genebra: WHO; 2017 [acesso em 12 nov 2015]. Disponível em: http://apps.who.int/iris/bitstream/handle/10665/258690/9789290341154-por. pdf; jsessionid=4253981D8B8659CA7CEC87DA28A9A3EC? sequence $=5$.

10. Minayo MC de S. O desafio do conhecimento: pesquisa qualitativa em saúde. 14. ed. [Internet]. São Paulo: Hucitec; 2014. Disponível em: https://www.researchgate.net/publication/33023325 O desafio do conhecimento Pesquisa qualitativa em saude.

11. Vendruscolo C, Adamy EK, Weber ML et al. Mestrado Profissional: promovendo a transformação da práxis em enfermagem. In.: Dickman I (Org.). DNA educação. São Paulo: Dialogar; 2018.

12. Global Advanced Practice Nursing Symposium. United State of America; 2014. Philadelphia: National Nursing Centers Consortium (NNCC); 2014.

13. Coordenação de Aperfeiçoamento de Pessoal de Nível Superior (CAPES - Brasil). Edital n. 27 de 2016. Apoio a programas de pós-graduação da área de enfermagem - modalidade mestrado profissional. [Internet]. 2016 [acesso em 12 nov 2015]. Disponível em: https://www.capes.gov.br/images/stories/ download/editais/05122016-Edital-27-\%20Capes-COFEN.pdf.

14. Oliveira JSA de, Pires DEP de, Alvarez AM, Sena RR de, Medeiros SM de, Andrade SR de.Trends in the job market of nurses in the view of managers. Rev bras enferm. [Internet]. 2018 [acesso em 12 nov 2019]; 71(1). Disponível em: http://dx.doi.org/10.1590/0034-7167-2016-0103.

15. Machado MH, Aguiar Filho W, Lacerda WF de, Oliveira E de, Lemos W, Wermelinger M, et al. Características Gerais da Enfermagem: o perfil sócio demográfico. Enfer. Foco. [Internet]. 2016 [acesso em 22 mar 2019]; 7(esp). Disponível em: http://revista.cofen.gov.br/index.php/enfermagem/article/ view/686/296.

16. Backes DS, Backes MS, Erdmann AL, Büscher A. O papel profissional do enfermeiro no Sistema Único de Saúde: da saúde comunitária à estratégia de saúde da família. Ciênc. Saúde Coletiva [Internet]. 2012 [acesso em 25 fev 2020]; 17(1). Disponível em: http://www.scielo.br/pdf/csc/v17n1/a24v17n1.pdf.

17. Araújo TAM de, Vasconselos ACCP de, Pessoa TRRF, Forte FDS. Multiprofessionality and interprofessionality in a hospital residence: preceptors and residents'view. Interface (Botucatu). [Internet]. 2017 [acesso em 25 fev 2020]; 21(62). Disponível em: http://www.scielo.br/pdf/icse/v21n62/1807-5762icse-1807-576220160295.pdf.

18. Ministério da Saúde (BR). Portaria n. 1.996/GM, de 20 de agosto de 2007. Dispõe sobre as diretrizes para a implementação da Política Nacional de Educação Permanente em Saúde. Diário Oficial da união, Brasília, 23 ago. 2007. Seção1.

19. Vendruscolo C, Zocche D, Dutra AT. Produção do plano de educação permanente em saúde: relato de experiência no oeste catarinense. Cogitare enferm. [Internet]. 2015 [acesso em 22 abr 2018]; 20(3). Disponível em: http://dx.doi.org/10.5380/ce.v20i3.40339. 
20. Freire P. Pedagogia do oprimido. 59. ed. Rio de Janeiro: Paz e Terra; 2015.

21. Martinez EA, Tocantins FR, Souza SR de. The specificities of communication in child nursing care. Rev. Gaúch. Enferm. [Internet]. 2013 [acesso em 26 fev 2020]; 34(1). Disponível em: http://www.scielo.br/pdf/ rgenf/v34n1/en 05.pdf.

22. Cyrino AP, Schraiber LB. Promoção da saúde e prevenção de doenças: o papel da educação e da comunicação. In: Martins MA et al. (Org.). Clínica médica, volume 1: atuação da clínica médica, sinais e sintomas de natureza sistêmica, medicina preventiva, saúde da mulher, envelhecimento e geriatria, medicina laboratorial na prática médica. Barueri: Manole; 2009. p. 470-477.

23. Antunes J de M, Daher DV, Ferrari MFM. Preceptoria como lócus de aprendizagem e de coprodução de conhecimento. Rev. enferm. UFPE on line. [Internet]. 2017 [acesso em 26 fev 2020]; 11(10). Disponível em: https://periodicos.ufpe.br/revistas/revistaenfermagem/article/view/22612.

24. Glanzner $\mathrm{CH}$; Olschowsky A, Pai DD. Tavares JP, Hoffman DA. Avaliação de indicadores e vivências de prazer/sofrimento em equipes de saúde da família com o referencial da Psicodinâmica do Trabalho. Rev. Gaúch. Enferm. [Internet]. 2017 [acesso em 7 abr 2020]; 38(4). Disponível em: http://www.scielo.br/pdf/ rgenf/v38n4/1983-1447-rgenf-38-04-e2017-0098.pdf.

25. Egry EY. Um olhar sobre as boas práticas de enfermagem na atenção básica. Rev. bras. enferm. [Internet]. 2018 [acesso em 12 Jan 2020]; 71(3). Disponível em: http://www.scielo.br/pdf/reben/v71n3/ pt 0034-7167-reben-71-03-0930.pdf. 
COMO REFERENCIAR ESTE ARTIGO:

Vendruscolo C, Silva KJ da, Araújo JAD, Weber ML. Educação permanente e sua interface com melhores práticas em enfermagem na atenção primária à saúde. Cogitare enferm. [Internet]. 2021 [acesso em "colocar data de acesso, dia, mês abreviado e ano"]; 26. Disponível em: http://dx.doi.org/10.5380/ce.v26i0.72725.

Recebido em: 08/04/2020

Aprovado em: $23 / 07 / 2020$

Editora associada: Susanne Elero Betiolli

Autor Correspondente:

Carine Vendruscolo

Universidade do Estado de Santa Catarina - Florianópolis, SC, Brasil

E-mail: carine.vendruscolo@udesc.br

Contribuição dos autores:

Contribuições substanciais para a concepção ou desenho do estudo; ou a aquisição, análise ou interpretação de dados do estudo - CV, KJS, JADA, MLW

Elaboração e revisão crítica do conteúdo intelectual do estudo - CV

Aprovação da versão final do estudo a ser publicado - CV, KJS, JADA, MLW

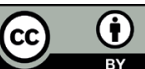

Copyright $\odot 2021$ Este é um artigo em acesso aberto distribuído nos termos da Licença Creative Commons Atribuição, que permite o uso irrestrito, a distribuição e reprodução em qualquer meio desde que o artigo original seja devidamente citado. 